\title{
Article \\ Development of a Novel Nordic Hamstring Exercise Performance Test Device: A Reliability and Intervention Study
}

\author{
Jesper Augustsson * (D) and Sofia Ryman Augustsson (D) \\ Department of Sport Science, Faculty of Social Sciences, Linnaeus University, 39182 Kalmar, Sweden; \\ sofia.rymanaugustsson@lnu.se \\ * Correspondence: jesper.augustsson@lnu.se; Tel.: +46-(0)705589752
}

Citation: Augustsson, J.; Augustsson, S.R. Development of a Novel Nordic Hamstring Exercise Performance Test Device: A Reliability and Intervention Study. Sports 2022, 10, 26. https://doi.org/10.3390/ sports10020026

Academic Editors: Gerald T. Mangine and Corrado Lupo

Received: 3 December 2021 Accepted: 18 February 2022 Published: 21 February 2022

Publisher's Note: MDPI stays neutral with regard to jurisdictional claims in published maps and institutional affiliations.

Copyright: (C) 2022 by the authors. Licensee MDPI, Basel, Switzerland. This article is an open access article distributed under the terms and conditions of the Creative Commons Attribution (CC BY) license (https:// creativecommons.org/licenses/by/ $4.0 /$ )

\begin{abstract}
There is evidence that a knee flexor exercise, the Nordic hamstring exercise (NHE), prevents hamstring injuries. The purpose of this study was therefore to develop, and to determine the reliability of, a novel NHE test device and, further, to determine the effectiveness of a 10-week low volume NHE program on NHE performance. Twenty female football (soccer) players, aged 16-30 years, participated in this study. From a kneeling position on the device, with the ankles secured under a heavy lifting sling, participants leaned forward in a controlled manner as far as possible (eccentric phase) and then returned to the starting position (concentric phase). A tape measure documented the forward distance achieved by the participants in $\mathrm{cm}$. Participants completed three separate occasions to evaluate test-retest reliability. Additionally, 14 players performed a low volume (1 set of 5 repetitions) NHE program once weekly for 10 weeks. No significant test-retest differences in NHE performance were observed. The intra-class correlation coefficient was 0.95 and the coefficient of variation was 3.54\% between tests. Mean improvement in the NHE performance test by the players following training was $22 \%(8.7 \mathrm{~cm}), p=0.005$. Our test device reliably measured NHE performance and is easy to perform in any setting. Further, NHE performance was improved by a 10-week low volume NHE program. This suggests that even a small dose (1 set of 5 repetitions once weekly) of the NHE may enhance NHE performance.
\end{abstract}

Keywords: soccer; hamstring muscles; soft tissue injuries; resistance training; athletic performance

\section{Introduction}

Hamstring muscle injury (and reinjury) is the most common muscle injury in many sports including football [1-3] and track and field [4]. Acute hamstring injury can be divided into at least two categories: high-speed running or stretching-type injuries [5]. The most common hamstring injury type typically occurs during high-speed running [6]. In several intervention studies researchers have used an eccentric strengthening protocol of the knee flexors that have successfully reduced the incidence rates of hamstring injuries [7-9]. Further, weak eccentric hamstrings strength has been established as an important modifiable risk factor for hamstring injuries [10]. The most common exercise performed in injury prevention programs is the Nordic hamstring exercise (NHE) [11]. The predominant way the NHE has been performed in research is eccentrically (where athletes lean forward and then fall to the floor in a controlled fashion, catching themselves with their hands). In sports, however, it is relatively common for strength and conditioning coaches and physiotherapists alike to have the athletes perform the exercise eccentrically-concentrically. Further, some elite athletes can perform a full NHE to the floor and back without a break point, in other words an eccentric-concentric NHE. As the NHE has recently been recognized to decrease the risk of hamstring injuries among athletes by half [12], it could be said that a large amount of scientific evidence now supports the use of this exercise to prevent hamstring injuries. Yet it is an elusive exercise, as there is no consensus on how to use it effectively in clinical practice when it comes to e.g., dosing, and further, today 
there is no simple and practical field-test to evaluate NHE performance. Currently, the gold standard to assess the effect of a NHE program on knee flexor strength is isokinetic dynamometry [13]; however, the validity of this method for predicting hamstring strain risk has been questioned [14]. Moreover, isokinetic dynamometry is expensive and rarely used outside the laboratory setting. Handheld dynamometry is an assessment tool used in the clinic, in research and by strength professionals. Research has shown, however, that this test may have drawbacks when it comes to collecting reliable and valid data $[15,16]$. More recently, several devices for the assessment of hamstring strength have been developed [17-19]. Typically, these devices use load cells where force data are transferred to a personal computer through a recording unit. Subsequently, the data are analyzed with custom data software. Alternative testing methods, which simply use the NHE itself to the dynamometry-based hamstring assessment tools, are currently lacking.

Therefore, the purpose of this study was to develop, and to determine the reliability of, a novel, simple and easy to use NHE test device. In addition, this study aimed to determine the effectiveness of a low-volume NHE intervention on NHE performance in female football (soccer) players.

\section{Materials and Methods}

\subsection{Participants}

Twenty female footballs players were recruited to the study. Coaches from two female football teams, from the second and fourth highest division in Sweden respectively, were contacted by telephone and the participants were introduced to the study during a visit at one of their practice sessions. The inclusion criteria included being a female athlete aged 16-30 years, participating and competing in football. Table 1 reports the characteristics of participants. The exclusion criteria were knee, hip or back injury prior to testing and training within six months of the study. Prior to inclusion, subjects were informed of the benefits and risks of participation before providing written informed consent.

Table 1. Characteristics of participants $(n=20)$.

\begin{tabular}{cc}
\hline Characteristics & Mean \pm SD \\
\hline Age, year & $20 \pm 4$ \\
Height, $m$ & $1.69 \pm 0.06$ \\
Weight, $\mathrm{kg}$ & $63 \pm 6$ \\
Football practice, hours per week & $5.4 \pm 1$ \\
\hline
\end{tabular}

\subsection{Procedures}

The same investigator collected the reliability NHE performance data on the participants at three separate sessions on different days, five to seven days apart. The first session served as a familiarization session and on the following two occasions NHE performance, using the novel NHE test, was determined. Subsequently, one of the teams (14 players) participated in the exercise intervention part of the study in which the participants performed a low volume (1 set of 5 repetitions) NHE program once per week for 10 weeks.

\subsection{Development of the Test Device}

The participants were tested for NHE performance using a device that consisted of a balance-pad (Airex, Sins, Switzerland) and a board $(55 \times 120 \times 2 \mathrm{~cm})$ that rested on three transverse wood studs $(41 \times 4.5 \times 7 \mathrm{~cm})$. See Figure 1 for testing set-up. A non-elastic roundsling with an effective working length of $100 \mathrm{~cm}$ (GVP Safety, Sweden) was placed around the board, connected by a strap. Further, a trestle (height $73 \mathrm{~cm}$ ) held a board via two straps onto which a steel band was attached. One end of a soft measuring tape ran under the steel band whereas the other end of the measuring tape was connected to a strap. Lastly, a measuring stick was used to position the measuring tape, via the strap, at $80 \mathrm{~cm}$ above knee height on each participant's torso. 


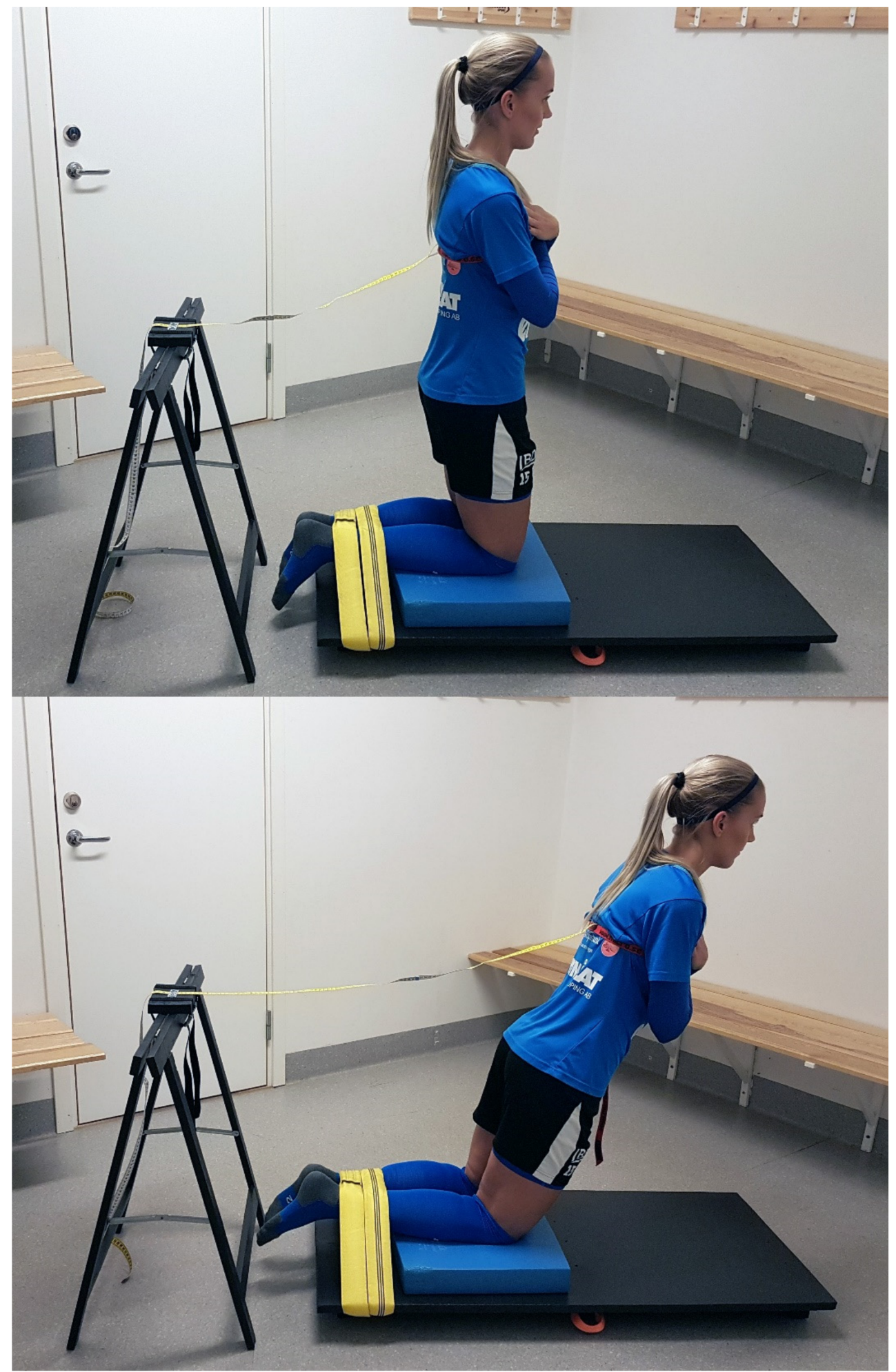

Figure 1. Testing set-up. Upper panel: The participants were placed in a kneeling position over the padded board, ankles secured under a roundsling and arms across the chest. The measuring tape was placed on the participant's torso via a strap, standardized at a height of $80 \mathrm{~cm}$ above the knees. Lower panel: Participants leaned forward in a slow, controlled manner as far as possible (eccentric phase) and then returned to the starting position (concentric phase). The tape measure documented the forward distance achieved by the participants in $\mathrm{cm}$. 


\subsection{Experimental Set-Up}

The participants performed a warm-up consisting of 5-min of ergometer cycling at $50 \mathrm{~W}$ and 1 set of 15 repetitions of squats, standing toe raises and hip bridges, respectively. The participants were then placed in a kneeling position over the padded board, ankles secured under the roundsling, the lateral malleolus aligned with the edge of the board and arms across the chest. Five submaximal NHE repetitions (at approximately $50 \%$ effort) where the participants leaned forward in a slow, controlled manner (eccentric phase) and then returned to the starting position (concentric phase) were then performed. This was followed by three submaximal, eccentric phase only, NHE repetitions (at approximately $80 \%$ effort) where the participants leaned forward and then fell to the floor in a controlled fashion, catching themselves with their hands. The measuring tape was then firmly placed on the participants' torsos via the strap, standardized at a height of $80 \mathrm{~cm}$ above the knees. The trestle, attached to the other end of the measuring tape, was placed behind the participants and adjusted as to take the slack out of the measuring tape. Subsequently, three maximal trials of eccentric-concentric NHE repetitions were performed, where participants leaned forward in a slow, controlled manner as far as possible (eccentric phase) and then returned to the starting position (concentric phase). The maximal NHE trials were separated by a standardized 1-min rest period to allow for recovery and avoid fatigue. The tape measure documented the forward distance achieved by the participants in $\mathrm{cm}$. If participants increased their performance in all three trials, one or two additional NHE repetitions were performed. Verbal commands to the participants were standardized and encouraging. A single investigator, a physical therapist that had more than 25 years of experience of testing and training athletes and patients, monitored all tests and the performance of all trials. Trials were only regarded as successful if the participants held trunk and hips in a neutral position during the NHE repetitions. The tests took place in a secluded room at the respective team facilities five to seven days apart.

\subsection{Exercise Intervention Protocol}

Following the reliability NHE performance part of the study, one of the teams (14 players) performed a low volume (1 set of 5 repetitions) NHE program once per week for 10 weeks. As part of the football practice warm-ups, the players performed five submaximal eccentric-concentric NHE repetitions (at approximately 50\% effort) and five submaximal eccentric NHE repetitions (at approximately 80\% effort). After these progressive warm-up repetitions, the players performed five maximal eccentric-concentric NHE repetitions. The players performed the NHE on the football field in pairs (i.e., with a partner), where one player assisted by holding the ankles and acting as a counterweight. The way the NHE was performed in the intervention did not differ from the tests. The investigators supervised all training sessions. Verbal commands to the players were standardized and encouraging. Data from players who did not attend at least $70 \%$ of the training sessions were not included in the analysis, as recommended by Weatherwax et al. [20]. All players performed the novel NHE test within seven days before and after the 10-week training intervention. No adverse events, in the form of injury, occurred during the 10-week training intervention.

\subsection{Statistical Analyses}

All statistical analyses were performed using IBM SPSS Statistics (version 26, IBM, Armonk, NY, USA) except for the statistical power analysis, where PS-Power and Sample Size Calculation (version 3, W.D. Dupont \& W.D. Plummer, Nashville, TN, USA) was used. The results are presented as means with SDs. To estimate the test-retest reliability of the NHE test, intraclass correlation coefficients (ICC) [21] with the two-way random effects model of the measurements with $95 \%$ confidence interval (CI) were used. The ICC were classified in the following manner: greater than 0.90 , high reliability; between 0.80 to 0.89 , good reliability; between 0.70 to 0.79 , fair reliability and values less than 0.69 , poor reliability [22]. Further, within-subject variation was determined using typical error expressed as a coefficient of variation (CV) [23]. A paired samples t-test was used to 
detect significant test-retest differences. The significance levels for all analyses were set to $p<0.05$. The effect size was calculated for determining the magnitude of the training effect, using the following formula: Pre-post effect size = posttest mean - pretest mean $/$ pretest SD [24]. A scale for determining the magnitude of effect size in trained athletes was used that identified $<0.25$ as representing a trivial effect, $0.25-0.5$ a small effect, $0.50-1.0$ a moderate effect and 1.0 or greater as a large effect [24]. Statistical power analysis: Based on a hypothesized $20 \%$ difference in performance as a result of the NHE intervention, 10 was the estimated number of participants required to achieve a power of 0.90 . Twenty percent improvement in performance, as recommended by Grant et al. [25], represents a meaningful clinical difference. This study was designed to recruit a minimum of 14 participants to allow for potential dropout.

\section{Results}

No significant test-retest differences were observed in NHE test performance by the participants. Mean \pm SD forward distance achieved for test 1 was $40.5 \mathrm{~cm} \pm 7.2$ vs. $41.4 \mathrm{~cm} \pm 7.4$, for test $2(p=0.064)$. The ICC value was 0.95 , the CI $0.87-0.98$ and the CV 3.54\%. NHE test performance significantly improved in the players following 10 weeks of NHE intervention. Mean improvement in NHE test performance for the players $(n=11)$ following training, assessed by the novel NHE test, was $22 \%(8.7 \mathrm{~cm} \pm 8.1)$, $p=0.005$. The effect size was determined to be 1.7, representing a large effect. All players included in the statistical analysis completed at least $70 \%$ of the training sessions, with an average attendance of $93 \%$. The figures of descriptive data show test-retest differences (Figure 2) and pre-post intervention changes (Figure 3) in NHE performance, respectively, in the participants.

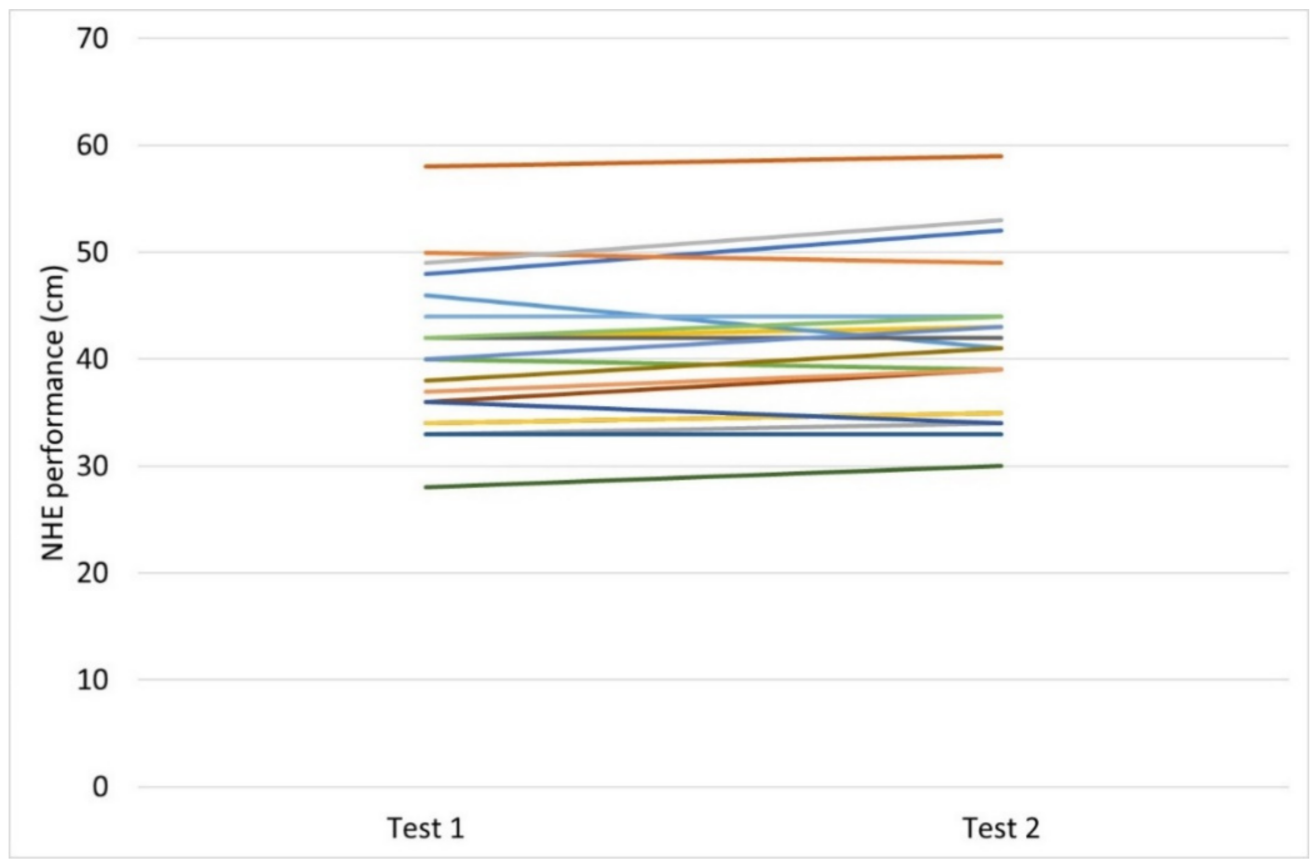

Figure 2. Descriptive data for test-retest differences in NHE performance $(\mathrm{cm})$ in the participants $(n=20)$. 


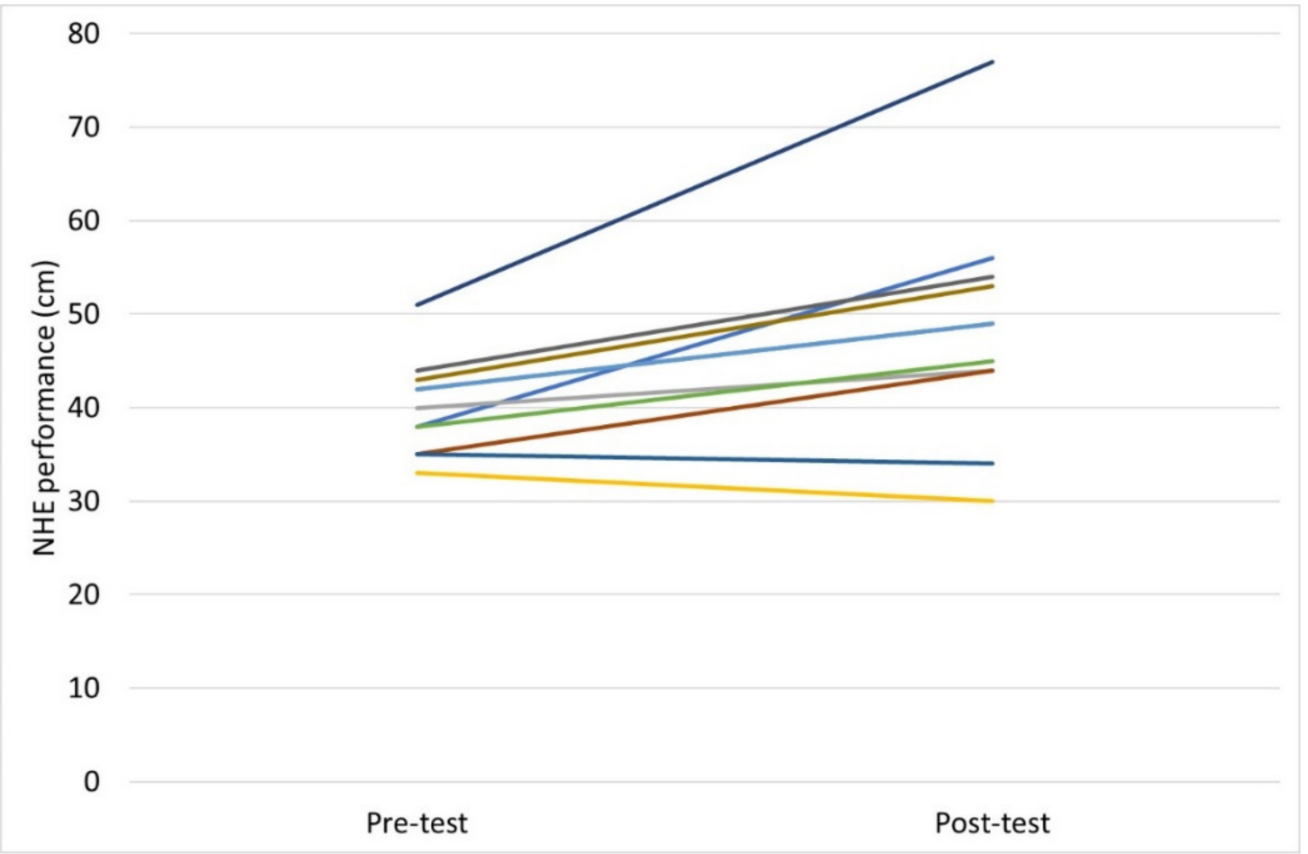

Figure 3. Descriptive data for pre versus post training intervention changes in NHE performance $(\mathrm{cm})$ in the participants $(n=11)$.

\section{Discussion}

The main finding of this study was that the novel field-based test device of NHE performance showed high reliability (ICC $=0.95)$ in female football players. Further, NHE test performance was significantly improved $(22 \%)$ by a low volume (1 set of 5 repetitions once per week) NHE program performed for 10 weeks.

In recent years, several studies have been published on new devices for the assessment of knee flexor strength [17-19]. One of these devices [17] has been used in research [26-28] and has since become commercially available, known as the NordBord testing system [29]. Whilst we recognize the importance of these new devices in research and in practice, they are relatively expensive and not an option for many sports teams and athletes. Our device is a practical and easy to perform field-based test that uses the NHE itself to measure NHE performance at a minimal cost and therefore may offer an inexpensive alternative for physical therapists, researchers, strength professionals, sports teams and athletes alike.

To our knowledge, this is the first intervention study investigating the effect of the NHE performed both eccentrically and concentrically. We noted a significant increase in NHE performance (22\%) after 10 weeks of training once weekly. This is in contrast to a recent study by Medeiros et al. [30] in which an 8-week NHE program performed eccentrically once weekly did not result in greater hamstring strength of football players. The different results may be explained by several factors. For example, changes in strength in the study by Medeiros et al. [30] was measured through isokinetic dynamometry, a test that may not be sensitive to improvements in isotonic strength [31]. Furthermore, the relationship between hamstring strength recorded isokinetically and NHE strength assessed by the eccentric hamstring strength device developed by Opar et al. [17] was poorly correlated [26]. The low association between these tests implies that they might measure different qualities of muscle strength.

The training volume in the present study was low: 1 set of 5 repetitions per week (not including the warm-up repetitions). In a recent systematic review and meta-analyses [11] on the effect of NHE training volume, it was concluded that low training volumes may be appropriate for athletes since low training volumes can produce large-to-very large improvements in knee flexor strength. A minimal dosage for the NHE has yet to be determined; however, we believe that the 1 set of 5 repetitions per week protocol used in 
our study is probably at the very end of the low training volume spectrum where changes in strength still occur. We also believe that by increasing the training volume it would be possible to attain larger increases in strength; however, doing so may very well lead to lower compliance in football players [32]. Moreover, in the short term the NHE may detrimentally affect e.g., sprint performance. Recently, it was noted that an NHE session reduced maximal sprint performance in athletes up to $48 \mathrm{~h} \mathrm{[33].} \mathrm{Therefore,} \mathrm{with} \mathrm{the} \mathrm{aim} \mathrm{of}$ keeping compliance and adherence among the athletes at its highest, perhaps a compromise when it comes to training volume is to be recommended.

There are two possible origins of improvements in NHE performance by the players in the intervention part of our study: neural adaptation (a learning effect as a result of strength training in which adaptive changes occur within the nervous system) and muscle hypertrophy. It is widely considered that neural adaptation, rather than hypertrophy, plays the dominant role in increases in performance during the initial phase of strength training [34]. Moreover, it seems as if high-load strength training results in greater neural adaptations than low-load strength training [35]. In the present study, the players performed each NHE with maximal effort/intensity. It is therefore suggested that the increases in NHE performance that were observed in the present study may be explained mainly by neural adaptation (although adaptation in the form of hypertrophy most likely occurred as well).

In studies on the NHE, this exercise is normally performed eccentrically $[8,10,11,17,26,27,30]$. In contrast, the NHE repetitions were, as mentioned earlier, performed eccentricallyconcentrically in our study. This is, however, the way repetitions generally are performed in strength training and testing when it comes to key exercises such as the bench press and barbell squat. Benefits from performing a combined eccentric-concentric muscle action instead of only the eccentric phase of the NHE may include that the total amount of work is higher (a "full" repetition compared with a "half" repetition). Further, the hamstrings act both eccentrically and concentrically during the test and thus arguably more closely mimic sports movements such as running and jumping.

There are some of limitations to the current study. The generalizability of the present study is limited to female football players. Further studies on other athletic populations are therefore desirable. In addition, the question of the validity of the novel measurement should be addressed. Our test device assesses NHE performance rather than knee flexor strength. Nonetheless, to validate against the gold standard for measuring knee flexor strength-isokinetic dynamometry-is something for future research. Further, the second part of the study in which the players performed the NHE intervention lacked a control group. However, the players can be considered as their own controls because they were tested twice (with no significant difference between tests) before the intervention [36]. Finally, to minimize the risk of injury the players performed a warm-up that included submaximal repetitions of NHE before both testing and training. However, we believe the improvements among the players originate from the maximal NHE repetitions and the effect of the warm-up on NHE test performance to be negligible.

\section{Conclusions}

The novel test device reliably measured NHE performance in female football players. With the help of this portable test device, planning and monitoring of various NHE interventions is possible in a quick, easy, inexpensive and reliable way. Further, NHE performance was improved by a low volume 10-week NHE program. This suggests that even a small dose ( 1 set of 5 repetitions once per week) of the NHE may improve NHE performance, but optimal dosing is still unclear [11].

Author Contributions: Conceptualization, J.A. and S.R.A.; methodology, J.A. and S.R.A.; formal analysis, J.A. and S.R.A.; investigation, J.A. and S.R.A.; data curation, J.A. and S.R.A.; writingoriginal draft preparation, J.A. and S.R.A.; writing-review and editing, J.A. and S.R.A. All authors have read and agreed to the published version of the manuscript. 
Funding: This study was supported by the Medical Research Council of Southeast Sweden (Funding number: FORSS-937450).

Institutional Review Board Statement: The study design, documentation and procedures were all approved by the Swedish Ethical Review Authority 29 May 2020, in accordance with the declaration of Helsinki (Dnr 2020-01366).

Informed Consent Statement: Written informed consent was obtained from all subjects involved in the study.

Data Availability Statement: The data presented in this study are available on request from the corresponding author.

Acknowledgments: The authors would like to thank the players that participated in this study, and their coaches.

Conflicts of Interest: The authors declare no conflict of interest.

\section{References}

1. Ekstrand, J.; Hägglund, M.; Waldén, M. Injury incidence and injury patterns in professional football: The UEFA injury study. Br. J. Sports Med. 2011, 45, 553-558. [CrossRef] [PubMed]

2. Ekstrand, J.; Hägglund, M.; Waldén, M. Epidemiology of muscle injuries in professional football (soccer). Am. J. Sports Med. 2011, 39, 1226-1232. [CrossRef] [PubMed]

3. Hagglund, M.; Walden, M.; Ekstrand, J. Risk factors for lower extremity muscle injury in professional soccer: The UEFA Injury Study. Am. J. Sports Med. 2013, 41, 327-335. [CrossRef] [PubMed]

4. Malliaropoulos, N.; Papacostas, E.; Kiritsi, O.; Papalada, A.; Gougoulias, N.; Maffulli, N. Posterior thigh muscle injuries in elite track and field athletes. Am. J. Sports Med. 2010, 38, 1813-1819. [CrossRef]

5. Askling, C.; Tengvar, M.; Saartok, T.; Thorstensson, A. Sports related hamstring strains-two cases with different etiologies and injury sites. Scand. J. Med. Sci. Sports 2000, 10, 304-307. [CrossRef]

6. Brooks, J.H.; Fuller, C.W.; Kemp, S.P.; Reddin, D.B. Incidence, risk, and prevention of hamstring muscle injuries in professional rugby union. Am. J. Sports Med. 2006, 34, 1297-1306. [CrossRef]

7. Petersen, J.; Thorborg, K.; Nielsen, M.B.; Budtz-Jørgensen, E.; Hölmich, P. Preventive effect of eccentric training on acute hamstring injuries in men's soccer: A cluster-randomized controlled trial. Am. J. Sports Med. 2011, 39, 2296-2303. [CrossRef]

8. van der Horst, N.; Smits, D.W.; Petersen, J.; Goedhart, E.A.; Backx, F.J. The preventive effect of the nordic hamstring exercise on hamstring injuries in amateur soccer players: A randomized controlled trial. Am. J. Sports Med. 2015, 43, 1316-1323. [CrossRef]

9. Askling, C.; Karlsson, J.; Thorstensson, A. Hamstring injury occurrence in elite soccer players after preseason strength training with eccentric overload. Scand. J. Med. Sci. Sports 2003, 13, 244-250. [CrossRef]

10. Sugiura, Y.; Saito, T.; Sakuraba, K.; Sakuma, K.; Suzuki, E. Strength deficits identified with concentric action of the hip extensors and eccentric action of the hamstrings predispose to hamstring injury in elite sprinters. J. Orthop. Sports Phys. Ther. 2008, 38, 457-464. [CrossRef]

11. Cuthbert, M.; Ripley, N.; McMahon, J.J.; Evans, M.; Haff, G.G.; Comfort, P. The Effect of Nordic Hamstring Exercise Intervention Volume on Eccentric Strength and Muscle Architecture Adaptations: A Systematic Review and Meta-analyses. Sports Med. 2020, 50, 83-99. [CrossRef] [PubMed]

12. van Dyk, N.; Behan, F.P.; Whiteley, R. Including the Nordic hamstring exercise in injury prevention programmes halves the rate of hamstring injuries: A systematic review and meta-analysis of 8459 athletes. Br. J. Sports Med. 2019, 53, 1362-1370. [CrossRef] [PubMed]

13. Aagaard, P.; Andersen, J.L. Correlation between contractile strength and myosin heavy chain isoform composition in human skeletal muscle. Med. Sci. Sports Exerc. 1998, 30, 1217-1222. [CrossRef]

14. Green, B.; Bourne, M.N.; Pizzari, T. Isokinetic strength assessment offers limited predictive validity for detecting risk of future hamstring strain in sport: A systematic review and meta-analysis. Br. J. Sports Med. 2018, 52, 329-336. [CrossRef] [PubMed]

15. Scott, D.A.; Bond, E.Q.; Sisto, S.A.; Nadler, S.F. The intra- and interrater reliability of hip muscle strength assessments using a handheld versus a portable dynamometer anchoring station. Arch. Phys. Med. Rehabil. 2004, 85, 598-603. [CrossRef] [PubMed]

16. Thorborg, K.; Bandholm, T.; Schick, M.; Jensen, J.; Hölmich, P. Hip strength assessment using handheld dynamometry is subject to intertester bias when testers are of different sex and strength. Scand. J. Med. Sci. Sports 2013, 23, 487-493. [CrossRef] [PubMed]

17. Opar, D.A.; Piatkowski, T.; Williams, M.D.; Shield, A.J. A novel device using the Nordic hamstring exercise to assess eccentric knee flexor strength: A reliability and retrospective injury study. J. Orthop. Sports Phys. Ther. 2013, 43, 636-640. [CrossRef]

18. Giacomo, J.; Lahti, J.; Hegyi, A.; Gerus, P.; Morin, J. A new testing and training device for hamstring muscle function. Sport Perform. Sci. Rep. 2018, 1, 1-4.

19. Hickey, J.T.; Hickey, P.F.; Maniar, N.; Timmins, R.G.; Williams, M.D.; Pitcher, C.A.; Opar, D.A. A Novel Apparatus to Measure Knee Flexor Strength during Various Hamstring Exercises: A Reliability and Retrospective Injury Study. J. Orthop. Sports Phys. Ther. 2018, 48, 72-80. [CrossRef] 
20. Weatherwax, R.M.; Harris, N.K.; Kilding, A.E.; Dalleck, L.C. Incidence of V O2max Responders to Personalized versus Standardized Exercise Prescription. Med. Sci. Sports Exerc. 2019, 51, 681-691. [CrossRef]

21. Shrout, P.E.; Fleiss, J.L. Intraclass correlations: Uses in assessing rater reliability. Psychol. Bull. 1979, 86, 420-428. [CrossRef] [PubMed]

22. Domholdt, E. Physical Therapy Research: Principles and Applications, 2nd ed.; W.B. Saunders Company: Philadelphia, PA, USA, 2000.

23. Shechtman, O. The coefficient of variation as an index of measurement reliability. In Methods of Clinical Epidemiology; Doi, S.A.R., Williams, G.M., Eds.; Springer: Berlin/Heidelberg, Germany, 2013; pp. 39-49.

24. Rhea, M.R. Determining the magnitude of treatment effects in strength training research through the use of the effect size. J. Strength Cond. Res. 2004, 18, 918-920. [PubMed]

25. Grant, J.A.; Mohtadi, N.G.; Maitland, M.E.; Zernicke, R.F. Comparison of home versus physical therapy-supervised rehabilitation programs after anterior cruciate ligament reconstruction: A randomized clinical trial. Am. J. Sports Med. 2005, 33, $1288-1297$. [CrossRef] [PubMed]

26. van Dyk, N.; Witvrouw, E.; Bahr, R. Interseason variability in isokinetic strength and poor correlation with Nordic hamstring eccentric strength in football players. Scand. J. Med. Sci. Sports 2018, 28, 1878-1887. [CrossRef]

27. Chalker, W.J.; Shield, A.J.; Opar, D.A.; Rathbone, E.N.; Keogh, J.W.L. Effect of acute augmented feedback on between limb asymmetries and eccentric knee flexor strength during the Nordic hamstring exercise. PeerJ 2018, 6, e4972. [CrossRef] [PubMed]

28. Timmins, R.G.; Bourne, M.N.; Shield, A.J.; Williams, M.D.; Lorenzen, C.; Opar, D.A. Biceps Femoris Architecture and Strength in Athletes with a Previous Anterior Cruciate Ligament Reconstruction. Med. Sci. Sports Exerc. 2016, 48, 337-345. [CrossRef]

29. NordBord. NordBord Hamstring Testing System. Available online: https://valdperformance.com/nordbord/ (accessed on 28 June 2021).

30. Medeiros, T.M.; Ribeiro-Alvares, J.B.; Fritsch, C.G.; Oliveira, G.S.; Severo-Silveira, L.; Pappas, E.; Baroni, B.M. Effect of Weekly Training Frequency With the Nordic Hamstring Exercise on Muscle-Strain Risk Factors in Football Players: A Randomized Trial. Int. J. Sports Physiol. Perform. 2020, 15, 1026-1033. [CrossRef]

31. Augustsson, J.; Esko, A.; Thomeé, R.; Svantesson, U. Weight training of the thigh muscles using closed vs. open kinetic chain exercises: A comparison of performance enhancement. J. Orthop. Sports Phys. Ther. 1998, 27, 3-8. [CrossRef]

32. Bahr, R.; Thorborg, K.; Ekstrand, J. Evidence-based hamstring injury prevention is not adopted by the majority of Champions League or Norwegian Premier League football teams: The Nordic Hamstring survey. Br. J. Sports Med. 2015, 49, $1466-1471$. [CrossRef]

33. Alonso-Fernandez, D.; Lopez-Barreiro, J.; Garganta, R.; Taboada-Iglesias, Y. Acute impact of Nordic hamstring exercise on sprint performance after 24, 48 and 72 hours. Sports Biomech. 2021, 1-15. [CrossRef]

34. Sale, D.G. Neural adaptation to resistance training. Med. Sci. Sports Exerc. 1988, 20 (Suppl. 5), S135-S145. [CrossRef] [PubMed]

35. Jenkins, N.D.M.; Miramonti, A.A.; Hill, E.C.; Smith, C.M.; Cochrane-Snyman, K.C.; Housh, T.J.; Cramer, J.T. Greater Neural Adaptations following High- vs. Low-Load Resistance Training. Front. Physiol. 2017, 8, 331. [CrossRef] [PubMed]

36. Weiss, N.S.; Heckbert, S.R. Patients as their own controls in studies of therapeutic efficacy: Can we trust the results of nonrandomized trials? J. Gen. Intern. Med. 1988, 3, 381-383. [CrossRef] [PubMed] 